\title{
Chloroform and Cognitive Function in the General Population of the US Elderly: A Cross-Sectional Study
}

\section{Sohyae Lee}

Seoul National University College of Medicine Jin-Young Min veterans medical research institute

Kyoung-Bok Min ( $\nabla$ minkb@snu.ac.kr) Seoul National University College of Medicine https://orcid.org/0000-0001-9576-0093

\section{Research}

Keywords: chloroform, water disinfection, neurotoxicity, cognitive test, aging, obese

Posted Date: November 30th, 2021

DOI: https://doi.org/10.21203/rs.3.rs-1102490/v1

License: (c) (1) This work is licensed under a Creative Commons Attribution 4.0 International License. Read Full License 


\section{Abstract \\ Background}

Chloroform is a water disinfection by-product associated with hepatic, renal and neurotoxicity. High concentrations of chloroform are known to cause central nervous system depression; however, the association between blood chloroform levels and cognitive function in the general elderly population is unknown. In this study, we investigated the association between blood chloroform levels and cognitive function in the elderly US population $(n=782)$.

\section{Methods}

We analyzed blood chloroform levels and cognitive function, as measured by the digit symbol substitution test (DSST), from the 2011-2012 and 2013-2014 National Health and Nutrition Examination Surveys (NHANES) for participants aged 60 years and older. Blood chloroform levels were measured using capillary gas chromatography and mass spectrometry with selected-ion monitoring detection and istotope-dilution.

\section{Results}

After adjusting for all covariates, increases in log-transformed blood chloroform levels were significantly associated with decreased DSST scores $(\beta=-1.56, S E=0.57, p$-value 0.010$)$. Compared with individuals in the lowest quartile of blood chloroform, the regression coefficients were significantly lower among those in the second and third tertile (tertile $2 \beta=-3.00$ ( $S E=1.25$, $p$-value 0.022 ); tertile $3 \beta=-4.05$ ( $S E=$ 1.22 , $p$-value 0.002$)$ ). After stratification by obesity status, increases in log-transformed chloroform levels showed borderline significant associations with decreased DSST scores among the obese $(\beta=-1.71, \mathrm{SE}=$ 0.85, p-value 0.052).

\section{Conclusions}

Our finding suggest a possible link between blood chloroform levels and cognitive function in the US elderly population.

\section{Background}

Chlorination is one of the most widely used methods for disinfecting water supplies. Although disinfection decreases the risk of waterborne infectious and parasitic diseases, it results in the formation of disinfection by-products which pose various health risks. Trihalomethanes are the most predominant chlorine disinfection by-products and chloroform usually accounts for greater than $90 \%$ of the total trihalomethane concentration [1]. 
Chloroform has been formerly used as an anesthetic and is currently used as a processing solvent and in the production of refrigerants [2]. The general population is exposed to chloroform through direct ingestion of food and drinking water, inhalation of contaminated air, and dermal contact with water [3]. Chloroform exposure affects the central nervous system, liver, and kidneys, and has also been associated with adverse reproductive outcomes and cancer of the colon and bladder [3]. The neurological effects of chloroform have been well documented due to its use as an anesthetic, and high concentrations of chloroform are known to cause central nervous system depression; however, studies on the relationship between chloroform and cognitive function remain limited [3].

Cognitive function covers the mental processes involving knowledge acquisition, information manipulation and reasoning and is an integral component of healthy aging [4]. Subjective cognitive decline is present in $11.7 \%$ of the US elderly aged 65 years and older and affects the health and wellbeing of the elderly [5]. Despite this fact, few studies have evaluated the association between chloroform exposure and cognitive function. In a case series of 29 cases of chronic chloroform poisoning, a patient exposed to up to $100 \mathrm{cc}$ of daily chloroform reported symptoms such as slowing of intellect and weakness of memory [6]. Studies in factory workers exposed to chronic inhalation of chloroform reported symptoms including a lack of concentration and some workers showed significant changes on neurocognitive tests including the digit span test and digital symbol substitution test $[7,8]$.

Previous studies have only examined chloroform exposure in terms of ingestion or inhalation in small samples of factory workers or cases associated with chloroform poisoning. To the best of our knowledge, no studies have examined the potential association between blood chloroform levels and cognitive function in the elderly general population. In the present study, we aimed to assess the association between blood chloroform levels and cognitive function in elderly US general population by studying participants in the National Health and Nutrition Examination Survey (NHANES) between 2011 and 2014. In addition, we also examined potential effect modification according to obesity status.

\section{Methods}

\subsection{Study population}

The National Health and Nutrition Examination Surveys (NHANES), conducted by the Centers for Disease Control and Prevention's (CDC) National Center for Health Statistics (NCHS), collects biennial health examination data for a nationally representative sample of the US civilian, noninstitutionalized population using a complex, multistage, probability sampling design [9]. The survey consists of a questionnaire evaluating demographic, socioeconomic, dietary, and health-related factors, followed by a standardized health examination which consists of medical, dental, and physiological measurements as well as the collection of blood and urine specimens for laboratory testing [10].

The study population included participants from the 2011-2012 and 2013-2014 NHANES. A total of 19,931 individuals were included from both cycles, and 3,014 individuals participated in the DSST (digit 
symbol substitution test). Blood chloroform was measured in 1,357 of these subjects. Among these subjects, a total of 782 participants with blood chloroform levels at or above the detection limit $(n=902)$ with subsample weights $(n=862)$ and data for all covariates $(n=782)$ were included in the final study population.

\subsection{Cognitive tests}

Cognitive function was evaluated in all NHANES participants aged 60 years and older using the DSST. The DSST is a valid, sensitive measure of cognitive dysfunction and measures processing speed, working memory, and sustained attention $[11,12]$. The test consists of a paper form with a legend at the top containing 9 numbers paired with 9 different symbols, and 133 boxes containing the 9 different numbers. Participants are required to copy the corresponding symbols in the boxes that adjoin the numbers, and the total score is calculated as the total number of correct matches made in a two-minute period. All participants who did not need a proxy informant and were able to understand or read English, Spanish, Korean, Vietnamese, traditional or simplified Mandarin, or Cantonese and gave consent were eligible for cognitive function testing. Participants who had a communication problem, physical limitation, or were unable to make correct matches on the pretest were ineligible for testing $[13,14]$.

\subsection{Measurements of Chloroform Levels}

Chloroform was measured in a one-half sample of NHANES participants aged 12 years and older. Whole blood specimens were stored at $2-8^{\circ} \mathrm{C}$ and shipped to the National Center for Environmental Health, Atlanta, GA for analysis. Capillary gas chromatography and mass spectrometry with selected-ion monitoring detection and istotope-dilution was used to analyze chloroform concentrations. For values below the lower limit of detection, an imputed value of the lower limit of detection (LLOD) divided by square root of 2 was used. Approximately $33 \%$ of the study population had values below the LLOD. Due to the fact that the LLOD for chloroform differed for the 2011-2012 and 2013-2014 cycles, the analysis was limited to blood chloroform levels at or above the detection limit (LLOD for the 2011-2012 cycle: 2.10 $\mathrm{pg} / \mathrm{mL}$; LLOD for the 2011-2012 cycle: $0.0080 \mathrm{ng} / \mathrm{mL}$ ). The other trihalomethanes (bromoform, bromodichloromethane, and dibromochloromethane) measured during the NHANES 2011-2014 cycles were not analyzed due to the insufficiency of detectable levels (more than $60 \%$ of the measurements were below the LLOD) $[15,16]$.

\subsection{Other variables of interest}

Covariates were obtained from the NHANES 2011-2014 and included sex (male or female), age, ethnicity (non-Hispanic white, non-Hispanic black, Hispanic, or other), annual family income (less than $\$ 20,000$ or $\$ 20,000$ or more), education (less than high school, high school graduate, or more than high school), marital status (married, never married, widowed, divorced, separated, or living with partner), smoking status (never, former smokers, or current smoker), alcohol consumption (yes or no), physical activity (yes or no), and body mass index (BMI) (underweight ( $<18.5 \mathrm{~kg} / \mathrm{m}^{2}$ ), normal weight $\left(18.5-24.9 \mathrm{~kg} / \mathrm{m}^{2}\right.$ ), overweight $\left(25.0-29.9 \mathrm{~kg} / \mathrm{m}^{2}\right)$, or obese $\left(>30 \mathrm{~kg} / \mathrm{m}^{2}\right)$ ). Self-reported physical activity was evaluated using the following question: "In a typical week do you do any moderate-intensity sports, fitness, or recreational 
activities that cause a small increase in breathing or heart rate such as brisk walking, bicycling, swimming, or volleyball for at least 10 minutes continuously?" and alcohol consumption was evaluated using the following question: "In any one year, have you had at least 12 drinks of any type of alcoholic beverage?" BMI was calculated as the weight in kilograms divided by the square of height in meters.

\subsection{Statistical Analysis}

Because the distribution of chloroform levels was right-skewed, blood chloroform levels were logtransformed, and analyzed as both continuous and categorical variables by tertiles. Blood chloroform levels between 2.10 and $9.28 \mathrm{pg} / \mathrm{mL}$ were categorized as tertile 1 (T1), 9.30-16.90 pg/mL as T2, and 17.0$166.0 \mathrm{pg} / \mathrm{mL}$ as T3. Linear regression analysis was performed to determine the relationship between log chloroform levels and DSST scores. Beta coefficients and standard errors (SE) were reported. We compared each tertile of chloroform with the lowest tertile of exposure (reference group). Adjusted models were adjusted for all potential confounders including age, sex, race, income, education, marital status, smoking history, alcohol consumption, physical activity, and BMI. Linear regression models were stratified by obesity status in order to examine effect modification by BMI. Weighted estimates of the population parameters were applied to account for the complex sampling design of the NHANES. PROC SURVEY procedures of SAS 9.4 statistical package (SAS Institute, Cary, NC, USA) were used for analysis and the statistical significance was set at $\mathrm{a}=0.05$.

\section{Results}

Table 1 shows the characteristics of the study population. The average at interview was $69.1 \pm 0.4$ years (range: $60-80$ years) and $51.3 \%$ of the overall sample was comprised of females. Most study participants were non-Hispanic whites (45.8\%), not impoverished (76.5\%), had an education beyond high school (51.8\%), married (54.4\%), never smokers (49.9\%), alcohol consumers (67.1\%), had a sedentary lifestyle (60.9\%), and were obese (36.1\%). The mean DSST score was $52.0 \pm 1.0$. The geometric mean for blood chloroform was $11.59 \pm 0.85 \mathrm{pg} / \mathrm{mL}$ and levels ranged from 2.10 to $166.0 \mathrm{pg} / \mathrm{mL}$. 
Table 1

Characteristics of study participants

\section{Characteristics}

No of participants

Sex

Male

Female

Age at interview (year)

Age categories

$60-64$

65-69

$70-74$

$75-79$

80 and above

Ethnicity

Non-Hispanic white

Non-Hispanic black

Hispanic

Others

Annual Family Income

Less than $\$ 20,000$

$\$ 20,000$ and over

Education

Less than high school

High school graduate

More than high school
Mean \pm SD or $n(\%)$

782

$381(48.7 \%)$

401 (51.3\%)

$69.1 \pm 0.4$

261 (33.4\%)

168 (21.5\%)

$156(20.0 \%)$

85 (10.9\%)

$112(14.3 \%)$

358 (45.8\%)

$211(27.0 \%)$

$134(17.1 \%)$

79 (10.1\%)

$184(23.5 \%)$

$598(76.5 \%)$

$192(24.6 \%)$

185 (23.7\%)

405 (51.8\%)

${ }^{1}$ Response to the question: "In any one year, have you had at least 12 drinks of any type of alcoholic beverage?"

2 Response to the question: "In a typical week do you do any moderate-intensity sports, fitness, or recreational activities that cause a small increase in breathing or heart rate such as brisk walking, bicycling, swimming, or volleyball for at least 10 minutes continuously?" 


\section{Characteristics}

Marital status

Married

Never married

Widowed/divorced/separated

Smoking history

Never smoked

Ex-Smoker

Current Smoker

Alcohol consumption $^{1}$

Yes

No

Physical Activity ${ }^{2}$

Yes

No

BMI $\left(\mathrm{kg} / \mathrm{m}^{2}\right)$

Underweight $(<18.5)$

Normal weight (18.5-24.9)

Overweight (25.0-29.9)

Obesity (>30)

Digit symbol substitution test score

${ }^{1}$ Response to the question: "In any one year, have you had at least 12 drinks of any type of alcoholic beverage?"

2 Response to the question: "In a typical week do you do any moderate-intensity sports, fitness, or recreational activities that cause a small increase in breathing or heart rate such as brisk walking, bicycling, swimming, or volleyball for at least 10 minutes continuously?"

DSST scores were inversely associated with log chloroform concentrations, as log-transformed chloroform concentrations increased, DSST scores decreased (Figure 1). Linear regression analysis of log-transformed chloroform levels and DSST scores are shown in Table 2. DSST scores showed a 
significant negative association with log-transformed chloroform levels in both the unadjusted and adjusted models. A two-fold increase in blood chloroform was associated with a 3.28 (SE $=1.04$, $p$-value 0.004 ) and 1.56 (SE = 0.57, p-value 0.010) decrease in DSST scores in the unadjusted and adjusted models, respectively. Linear regression analysis between DSST scores and tertiles of log-transformed chloroform also showed significant negative associations, excluding the beta coefficient for tertile 2 in the unadjusted model which showed borderline significance ( $p$-value 0.091). Compared to the tertile 1 as the reference, tertiles 2 and 3 were associated with lower DSST scores in the unadjusted (tertile 2 beta $=$ $-4.02, \mathrm{SE}=2.31, \mathrm{p}$-value 0.091 ; tertile 3 beta $=-6.43, \mathrm{SE}=2.14, \mathrm{p}$-value 0.005 ) and adjusted models (tertile 2 beta $=-3.00, \mathrm{SE}=1.25, \mathrm{p}$-value 0.022 ; tertile 3 beta $=-4.05, \mathrm{SE}=1.22$, $\mathrm{p}$-value 0.002 ). Comparing tertiles 2 and 3 with the lowest tertile revealed a dose-response relationship in both the unadjusted and adjusted models.

Table 2

Linear regression analysis of chloroform and DSST scores

\begin{tabular}{|c|c|c|c|c|c|c|c|c|c|c|}
\hline \multirow{2}{*}{\multicolumn{2}{|c|}{$\begin{array}{l}\text { Chloroform } \\
\text { concentrations, } \\
\text { pg/mL }\end{array}$}} & \multirow[t]{2}{*}{$\mathrm{n}$} & \multirow{2}{*}{$\begin{array}{l}\text { Geometric } \\
\text { Mean } \pm \\
\text { SE }\end{array}$} & \multicolumn{3}{|c|}{ Unadjusted model } & \multicolumn{4}{|c|}{ Adjusted model ${ }^{1}$} \\
\hline & & & & $\begin{array}{l}\text { Beta } \\
\pm \text { SE }\end{array}$ & $\mathbf{P}$ & $\begin{array}{l}\text { P for } \\
\text { model } \\
\text { effects }\end{array}$ & $\begin{array}{l}\text { Beta } \pm \\
\text { SE }\end{array}$ & $\mathrm{P}$ & & $\begin{array}{l}P \text { for } \\
\text { model } \\
\text { effects }\end{array}$ \\
\hline \multicolumn{2}{|c|}{$\begin{array}{l}\text { Per two-fold } \\
\text { increase }\end{array}$} & 782 & $\begin{array}{l}11.59 \pm \\
0.85\end{array}$ & $\begin{array}{l}-3.28 \\
\pm \\
1.04\end{array}$ & 0.004 & & $\begin{array}{l}-1.56 \\
\pm \\
0.57\end{array}$ & 0.010 & & \\
\hline \multirow[t]{3}{*}{ Tertiles } & $\begin{array}{l}\text { Tertile } \\
1(2.10- \\
9.28)\end{array}$ & 258 & & \multicolumn{2}{|c|}{ Reference } & 0.014 & \multicolumn{3}{|c|}{ Reference } & 0.003 \\
\hline & $\begin{array}{l}\text { Tertile } \\
2(9.30- \\
16.90)\end{array}$ & \multicolumn{2}{|l|}{249} & $\begin{array}{l}-4.02 \\
\pm \\
2.31\end{array}$ & 0.091 & & \multicolumn{3}{|l|}{$\begin{array}{l}-3.00 \pm \\
1.25\end{array}$} & \\
\hline & $\begin{array}{l}\text { Tertile } \\
3(17.0- \\
166.0)\end{array}$ & \multicolumn{2}{|l|}{275} & $\begin{array}{l}-6.43 \\
\pm \\
2.14\end{array}$ & 0.005 & & \multicolumn{3}{|l|}{$\begin{array}{l}-4.05 \pm \\
1.22\end{array}$} & \\
\hline
\end{tabular}

${ }^{1}$ Adjusted for age, sex, race, income, education, marital status, smoking history, alcohol consumption, physical activity, and BMI

Table 3 presents the relationship between chloroform exposures and DSST scores after stratification by obesity status (BMI $\geq 30 \mathrm{~kg} / \mathrm{m}^{2}$ ). In the unadjusted model for the non-obese participants, a two-fold increase in blood chloroform was significantly associated with a 3.39 ( $S E=1.51$, p-value 0.033 ) decrease in DSST scores, and compared to tertile 1 as the reference, tertile 3 showed a negative association (beta $=5.84, S E=3.24, p$-value 0.081 ), with borderline significance. There were no statistically significant associations between blood chloroform and DSST scores in the adjusted model for the non-obese group. Among the obese participants, a two-fold increase in blood chloroform levels was associated with a 3.11 
$(S E=1.10, p$-value 0.008) and $1.71(S E=0.85, p$-value 0.052) decrease in DSST scores in the unadjusted and adjusted models, respectively. In the analysis between DSST scores and log-transformed chloroform tertiles for the obese group, compared to tertile 1 as the reference, tertile 2 showed a borderline significant association in the adjusted model (beta $=-3.25, \mathrm{SE}=1.62$, $\mathrm{p}$-value 0.054 ), and tertile 3 showed significant negative associations in both models (unadjusted model beta $=-7.76, \mathrm{SE}=2.92$, $\mathrm{p}$-value 0.012 ; adjusted model beta $=-5.53, \mathrm{SE}=1.89, \mathrm{p}$-value 0.006 ). Beta coefficients for tertile 2 and 3 , with tertile 1 as the reference, showed dose-response relationships.

Table 3

Relationship between blood chloroform and DSST scores, stratified by obesity status

Chloroform concentrations, $\mathrm{pg} / \mathrm{mL}$
Unadjusted model

\begin{tabular}{|c|c|c|c|c|}
\hline $\begin{array}{l}\text { Beta } \pm \\
\text { SE }\end{array}$ & $\mathbf{P}$ & $\begin{array}{l}P \text { for model } \\
\text { effects }\end{array}$ & $\begin{array}{l}\text { Beta } \pm \\
\text { SE }\end{array}$ & $P$ \\
\hline
\end{tabular}

\section{BMI}

$<30 \mathrm{~kg} / \mathrm{m}^{2}$

$\begin{array}{llllll}\text { Per two-fold increase } & 500 & \begin{array}{c}-3.39 \pm \\ 1.51\end{array} & 0.033 & \begin{array}{c}-1.37 \pm \\ 0.95\end{array} & 0.161\end{array}$

\begin{tabular}{|c|c|c|c|c|c|c|c|}
\hline \multirow[t]{2}{*}{ Tertiles } & \multirow{2}{*}{$\begin{array}{l}\text { Tertile } 1 \text { (2.13- } \\
9.42) \\
\text { Tertile } 2 \text { (9.43- } \\
16.9)\end{array}$} & \multirow{2}{*}{$\begin{array}{l}165 \\
157\end{array}$} & \multicolumn{2}{|c|}{ Reference } & \multirow[t]{2}{*}{0.206} & \multicolumn{2}{|c|}{ Reference } \\
\hline & & & $\begin{array}{l}-4.76 \pm \\
3.16\end{array}$ & 0.143 & & $\begin{array}{l}-2.55 \pm \\
1.88\end{array}$ & 0.185 \\
\hline & $\begin{array}{l}\text { Tertile } 3 \text { (17.0- } \\
\text { 166.0) }\end{array}$ & 178 & $\begin{array}{l}-5.84 \pm \\
3.24\end{array}$ & 0.081 & & $\begin{array}{l}-3.15 \pm \\
2.10\end{array}$ & 0.145 \\
\hline
\end{tabular}

\section{$\geq 30 \mathrm{~kg} / \mathrm{m}^{2}$}

$\begin{array}{llllll}\text { Per two-fold increase } & 282 & -3.11 \pm & 0.008 & -1.71 \pm & 0.052 \\ & 1.10 & & 0.85 & \end{array}$

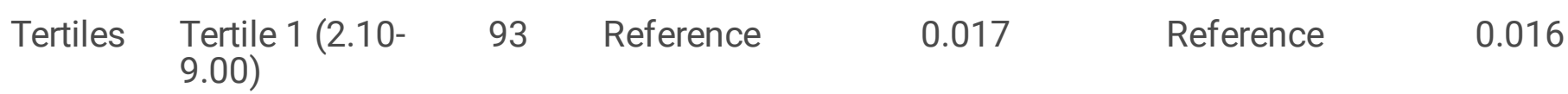

\begin{tabular}{|c|c|c|c|c|}
\hline $\begin{array}{l}\text { Tertile } 2 \text { (9.10- } \\
16.3)\end{array}$ & 92 & $\begin{array}{l}-2.52 \pm \\
3.00\end{array}$ & 0.408 & $\begin{array}{l}-3.25 \pm \\
1.62\end{array}$ \\
\hline $\begin{array}{l}\text { Tertile } 3 \text { (17.0- } \\
\text { 153.0) }\end{array}$ & 97 & $\begin{array}{l}-7.76 \pm \\
2.92\end{array}$ & 0.012 & $\begin{array}{l}-5.53 \pm \\
1.89\end{array}$ \\
\hline
\end{tabular}

${ }^{1}$ Adjusted for age, sex, race, income, education, marital status, smoking history, alcohol consumption, and physical activity

\section{Discussion}


This study aimed to determine whether there was an association between blood chloroform and cognitive function in the general elderly population. In this cross-sectional study of US elderly, we found that blood chloroform levels were negatively associated with cognitive function measured using the DSST. These results suggest that chloroform exposure in the general population may contribute to cognitive impairment as measured by the DSST.

Cognitive function refers to multiple mental processes including attention, learning, decision making, language, and memory and is an integral component of a healthy and independent lifestyle [4]. Cognitive impairment in the elderly may have a profound impact on an individual's activities of daily living including meal preparation and ability to manage medication regimens, resulting in poor health outcomes [5]. Identifying and reducing modifiable risk factors of cognitive impairment is essential to minimizing the poor health outcomes associated with cognitive impairment and improving the health and well-being of the elderly [5].

Chloroform is a water disinfection by-product widely dispersed in the environment which has been formerly used as an anesthetic in the past [3]. Its narcotic effects have been well documented; however studies on occupational or environmental exposures to chloroform and its relationship with cognitive function remain limited [17]. In addition, previous studies have evaluated chloroform exposure in terms of inhaled or ingested concentrations instead of blood concentrations. In line with the results of our study, previous studies have reported a relationship between chloroform and cognitive function. In a case series of 29 cases of chloroform addiction, one case reported symptoms of slowing of intellect and weakness of memory [6]. Other common symptoms included irritability, anxiety, depression, hallucinations, and hand tremor [6]. In a study conducted at a medicinal lozenge producing factory in the UK, 8 out of 7 women exposed to chronic inhalation exposure to chloroform concentrations ranging from 77 to 237 ppm reported feelings of a lack of concentration, depression, and irritability [7]. In a study of 61 workers exposed to long-term chloroform concentrations ranging from $0.87-28.9 \mathrm{ppm}$, workers experienced symptoms such as fatigue, dizziness, insomnia, and palpitations and significant changes were found in neurologic tests including the Simple Visual Reaction Time, Digital Symbol Substitution, and Digit Span test for some workers [8].

The molecular mechanism behind the association between chloroform and cognitive function is unclear; however, there are several possible mechanisms which may serve as an explanation [3]. Glutamate is a neurotransmitter which plays a key role in cognitive function [18]. In an in vitro study using mouse cortical wedges, chloroform concentrations of 3-6 mM antagonized responses of the glutamate receptor $\mathrm{N}$-methyl-D-aspartate [19]. Decreased serotonin neurotransmission is known to negatively influence cognitive function [20]. Another study in mice investigating the effects of oral administration of chloroform showed decreased levels of 5-hydroxyindoleacetic acid, the main metabolite of serotonin, in the midbrain [21]. In addition, chloroform may be associated with the changes in the calcium-dependent potassium conductance in neurons, which may play a role in cognition $[22,23]$. 
After stratification by obesity status statistically significant associations were observed among the obese, indicating that the obese may be more susceptible. Chloroform is lipophilic and concentrates mainly in tissues with high lipid content [3]. In an animal study, after 2.5 hours of deep anesthesia with chloroform, relative concentrations of chloroform were highest in adipose tissue followed by the brain, liver, kidney, and blood [24].

Chloroform is lipophilic and distributes to areas with high lipid density and therefore has a relatively high volume of distribution ( $\mathrm{Vd}$ ) [25]. In addition, because total body weight is correlated with $\mathrm{Vd}$ for lipophilic drugs and a drug with a high Vd has a longer elimination half-life, individuals with higher BMls may be more susceptible to the effects of chloroform [26].

Environmental routes of exposure to chloroform include inhalation to air polluted with chloroform, and oral and dermal routes from water contaminated water sources. A recent study investigating factors associated with chloroform exposure from the NHANES 2001-2011 cycles reported that elevated blood levels of chloroform were associated with taking a shower or bath within 6 hours of blood collection or being in a pool or hot tub or sauna within 24 hours, suggesting that contaminated water sources could be the source of chloroform exposure in the study population [27]. Median chloroform concentrations in tap water collected from the homes of NHANES 2001-2011 participants aged 12 and older ranged from 7.52 to $12.3 \mu \mathrm{g} / \mathrm{L}$, levels which are well below the WHO benchmark levels for drinking water quality $(300 \mu \mathrm{g} / \mathrm{l})$ and the US Environmental Protection Agency's maximum contaminant level goal of $70 \mu \mathrm{g} / \mathrm{L}$ [27-29]. These results suggest that the NHANES sample was exposed to low levels of chloroform well below the recommended levels. Although our findings require confirmation, low levels of chloroform exposure seem to have an effect on cognitive function.

To the best of our knowledge, this is the first population-based study to examine the relationship between blood chloroform levels and cognitive function measured by the DSST in the general elderly population. Despite this fact, our study has several limitations. Due to the cross-sectional nature of the study, we cannot assess any casual or temporal relationships. Although we cannot assess temporality, the presence of a dose-response relationship between blood chloroform levels and DSST scores could provide evidence for a causal relationship. Secondly, due to the cross-sectional nature of the data, we were unable to differentiate between acute and chronic exposure. Blood trihalomethane levels are known to increase and decrease within minutes to hours after exposure to daily activities including showering, bathing, and dishwashing; however, blood trihalomethane concentrations are thought to reflect steadystate blood concentrations due to the frequency of water use activities and slow partitioning out of physiological compartments like adipose tissue [30-32]. Thirdly, several covariates were self-reported and as a result are not free from bias. Lastly, although basic sociodemographic confounding variables were considered, we cannot exclude the possibility of residual confounding due to unmeasured confounders.

\section{Conclusion}


In conclusion, we found a significant negative association between blood chloroform levels and DSST scores in a representative sample of the US elderly population aged 60 years and older. Although the US Environmental Protection Agency has been controlling chloroform levels, levels of chloroform well below the recommended levels may be associated with cognitive decline in the elderly. Further studies should assess the causality behind this association and whether or not the effects of chloroform are reversible. If a casual association between blood chloroform and cognitive function in the general population is confirmed, this may indicate a need for stricter drinking water quality guidelines.

\section{List Of Abbreviations}

DSST, Digit symbol substitution test; NHANES, National Health and Nutrition Examination Surveys

\section{Declarations}

\subsection{Ethics approval and consent to participate}

Not applicable

\subsection{Consent for publication}

Not applicable

\subsection{Availability of data and materials}

The datasets generated and/or analyzed during the current study are available on the NHANES website, https://www.cdc.gov/nchs/nhanes/index.htm.

\subsection{Competing interests}

The authors declare that they have no competing interests.

\subsection{Funding}

This study was supported by Basic Science Research Program through the National Research Foundation of Korea, funded by the Ministry of Education, Science and Technology (Grants, NRF2019R1A2C1004966).

\subsection{Authors' contributions}

Conceptualization: SHL, KBM. Data curation: SHL, KBM. Formal analysis: SHL. Funding acquisition: KBM. Methodology: SHL, JYM, KBM. Writing - original draft: SHL, JYM. Writing - review \& editing: KBM, JYM. All authors have read and approved this manuscript. 


\subsection{Acknowledgements}

Not applicable

\section{References}

1. World Health Organization: Water, Sanitation, and Health Team. WHO guidelines for drinking water quality: training pack. In.: World Health Organization; 2000.

2. PubChem Compound Summary for CID 6212, Chloroform [https://pubchem.ncbi.nlm.nih.gov/compound/Chloroform] Accessed 15 April 2021.

3. Agency for Toxic Substances and Disease Registry (ATSDR): Toxicological Profile for Chloroform. In. Atlanta, GA: Public Health Service, U.S. Department of Health and Human Services; 1997.

4. Kiely KM: Cognitive Function. In: Encyclopedia of Quality of Life and Well-Being Research. Edited by Michalos AC. Dordrecht: Springer Netherlands; 2014: 974-978.

5. Subjective Cognitive Decline - A Public Health Issue [https://www.cdc.gov/aging/aginginfo/subjective-cognitive-decline-brief.html] Accessed 15 April 2021.

6. HEILBRUNN G, LIEBERT E, SZANTO PB: CHRONIC CHLOROFORM POISONING: CLINICAL AND PATHOLOGIC REPORT OF A CASE. Archives of Neurology \& Psychiatry 1945, 53(1):68-72.

7. Challen PJ, Bedford J, Hickish DE: Chronic chloroform intoxication. British journal of industrial medicine 1958, 15(4):243-249.

8. Li LH, Jiang XZ, Liang YX, Chen ZQ, Zhou YF, Wang YL: Studies on the toxicity and maximum allowable concentration of chloroform. Biomedical and environmental sciences: BES 1993, 6(2):179-186.

9. Johnson CL DS, Burt VL, Mohadjer LK: National Health and Nutrition Examination Survey: Sample design, 2011-2014. In., 2(162) edn: National Center for Health Statistics; 2014.

10. National health and nutrition examination survey [https://www.Cdc.Gov/nchs/nhanes/index.Htm] Accessed 15 April 2021.

11. Jaeger J: Digit Symbol Substitution Test: The Case for Sensitivity Over Specificity in Neuropsychological Testing. Journal of clinical psychopharmacology 2018, 38(5):513-519.

12. Wechsler D: WAIS Manual - Third Edition. New York: Psychological Corporation; 1997.

13. 2013-2014 Data Documentation, Codebook, and Frequencies: Cognitive Functioning (CFQ_H) [https://wwwn.cdc.gov/Nchs/Nhanes/2013-2014/CFQ_H.htm] Accessed 15 April 2021.

14. 2011-2012 Data Documentation, Codebook, and Frequencies: Cognitive Functioning (CFQ_G) [https://wwwn.cdc.gov/Nchs/Nhanes/2011-2012/CFQ_G.htm] Accessed 15 April 2021.

15. 2013-2014 Data Documentation, Codebook, and Frequencies: Volatile Organic Compounds and Trihalomethanes/MTBE - Blood (VOCWB_H) [https://wwwn.cdc.gov/Nchs/Nhanes/20132014/VOCWB_H.htm] Accessed 15 April 2021. 
16. 2011-2012 Data Documentation, Codebook, and Frequencies: Volatile Organic Compounds (VOCs) Trihalomethanes/MTBE/Nitromethane - Blood (VOCMWB_G) [https://wwwn.cdc.gov/Nchs/Nhanes/2011-2012/VOCMWB_G.htm] Accessed 15 April 2021.

17. Wawersik J: [History of chloroform anesthesia]. Anaesthesiologie und Reanimation 1997, 22(6):144152.

18. Rahn KA, Slusher BS, Kaplin Al: Glutamate in CNS neurodegeneration and cognition and its regulation by GCPII inhibition. Current medicinal chemistry 2012, 19(9):1335-1345.

19. Carlà V, Moroni F: General anaesthetics inhibit the responses induced by glutamate receptor agonists in the mouse cortex. Neuroscience letters 1992, 146(1):21-24.

20. Švob Štrac D, Pivac N, Mück-Šeler D: The serotonergic system and cognitive function. Translational neuroscience 2016, 7(1):35-49.

21. Kanada M, Miyagawa $M$, Sato $M$, Hasegawa $H$, Honma $T$ : Neurochemical profile of effects of 28 neurotoxic chemicals on the central nervous system in rats (1). Effects of oral administration on brain contents of biogenic amines and metabolites. Industrial health 1994, 32(3):145-164.

22. Caldwell KK, Harris RA: Effects of anesthetic and anticonvulsant drugs on calcium-dependent efflux of potassium from human erythrocytes. European journal of pharmacology 1985, 107(2):119-125.

23. Wang L, Kang H, Li Y, Shui Y, Yamamoto R, Sugai T, Kato N: Cognitive recovery by chronic activation of the large-conductance calcium-activated potassium channel in a mouse model of Alzheimer's disease. Neuropharmacology 2015, 92:8-15.

24. Chenoweth MB, Robertson DN, Erley DS, Golhke R: Blood and tissue levels of ether, chloroform, halothane and methoxyflurane in dogs. Anesthesiology 1962, 23:101-106.

25. Asad Mansoor NM: Volume of Distribution. Treasure Island, FL: StatPearls Publishing; 2020.

26. Hanley MJ, Abernethy DR, Greenblatt DJ: Effect of obesity on the pharmacokinetics of drugs in humans. Clinical pharmacokinetics 2010, 49(2):71-87.

27. Ashley DL, Smith MM, Silva LK, Yoo YM, De Jesús VR, Blount BC: Factors Associated with Exposure to Trihalomethanes, NHANES 2001-2012. Environmental science \& technology 2020, 54(2):10661074.

28. World Health Organization: Guidelines for drinking-water quality: fourth edition incorporating the first addendum. In. Geneva; 2017.

29. Agency EP: National Primary Drinking Water Regulations: Stage 2 Disinfectants and Disinfection Byproducts Rule, Final Rule. In.: Federal Register; 2006.

30. Backer LC, Ashley DL, Bonin MA, Cardinali FL, Kieszak SM, Wooten JV: Household exposures to drinking water disinfection by-products: whole blood trihalomethane levels. Journal of exposure analysis and environmental epidemiology 2000, 10(4):321-326.

31. Blount BC, Backer LC, Aylward LL, Hays SM, LaKind JS: Human Exposure Assessment for DBPs: Factors Influencing Blood Trihalomethane Levels. In: Encyclopedia of Environmental Health. Edited by Nriagu JO. Burlington: Elsevier; 2011: 100-107. 
32. Nuckols JR, Ashley DL, Lyu C, Gordon SM, Hinckley AF, Singer P: Influence of tap water quality and household water use activities on indoor air and internal dose levels of trihalomethanes.

Environmental health perspectives 2005, 113(7):863-870.

\section{Figures}

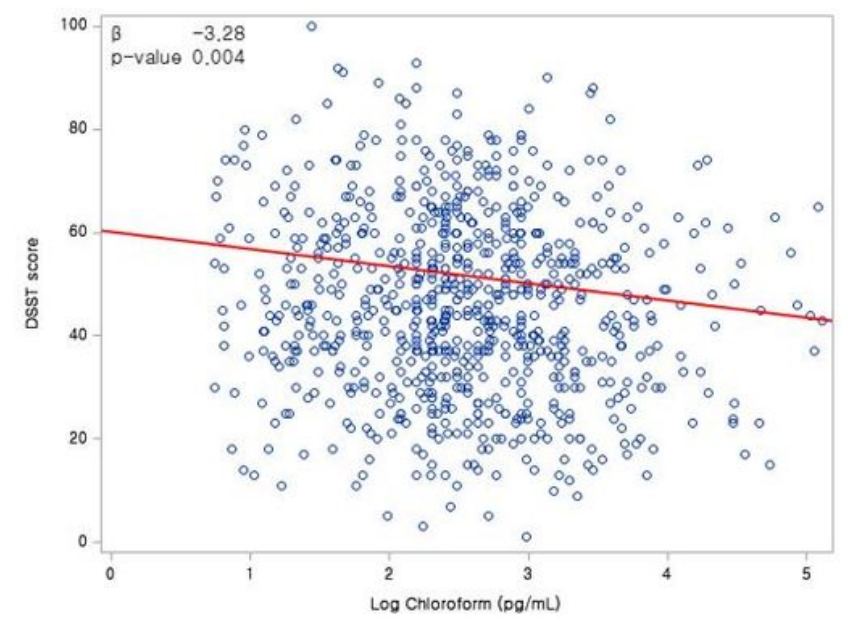

(a) Total population

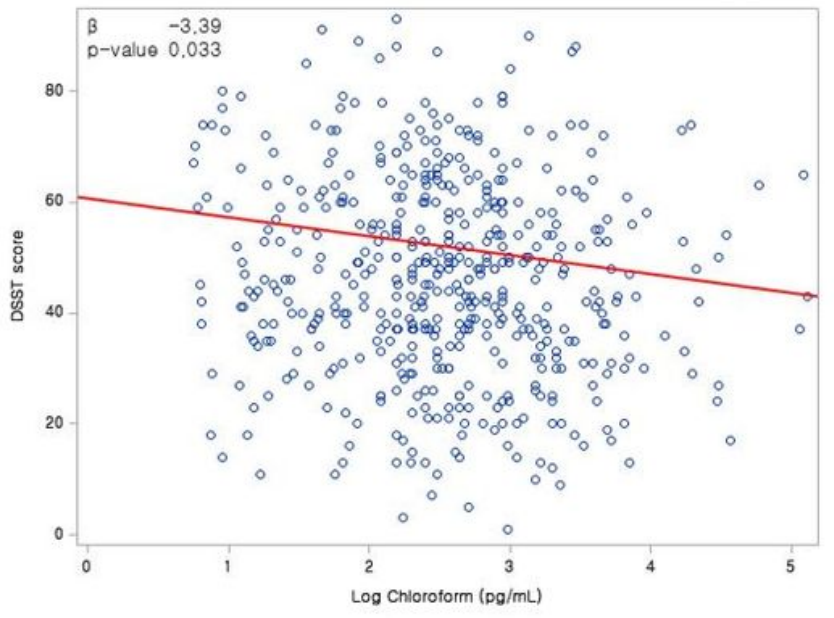

(b) $\mathrm{BMI}<30 \mathrm{~kg} / \mathrm{m}^{2}$

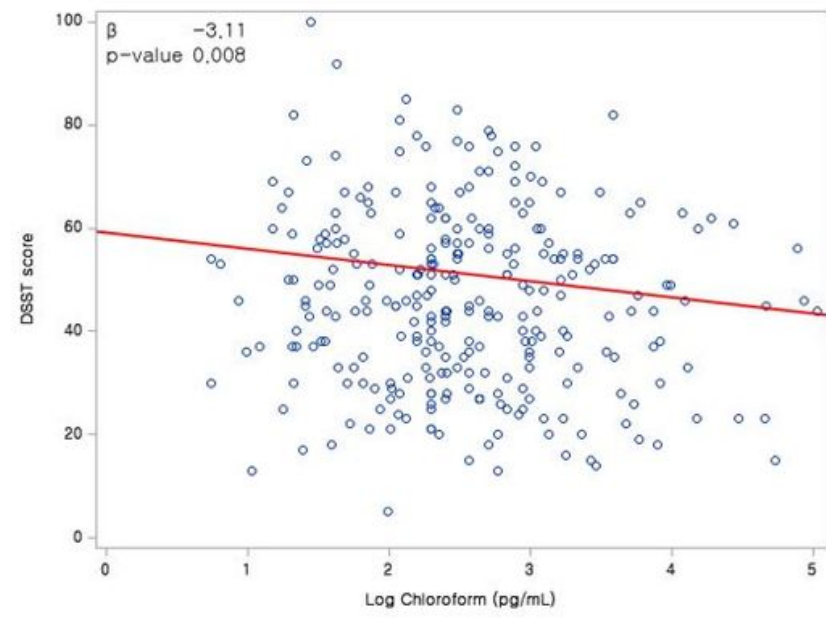

(c) $\mathrm{BMI} \geq 30 \mathrm{~kg} / \mathrm{m}^{2}$

\section{Figure 1}

Scatter plot of log chloroform ( $\mathrm{pg} / \mathrm{mL}$ ) and DSST scores for the (a) total population, (b) BMI $<30 \mathrm{~kg} / \mathrm{m} 2$, (3) $\mathrm{BMI} \geq 30 \mathrm{~kg} / \mathrm{m} 2$ 